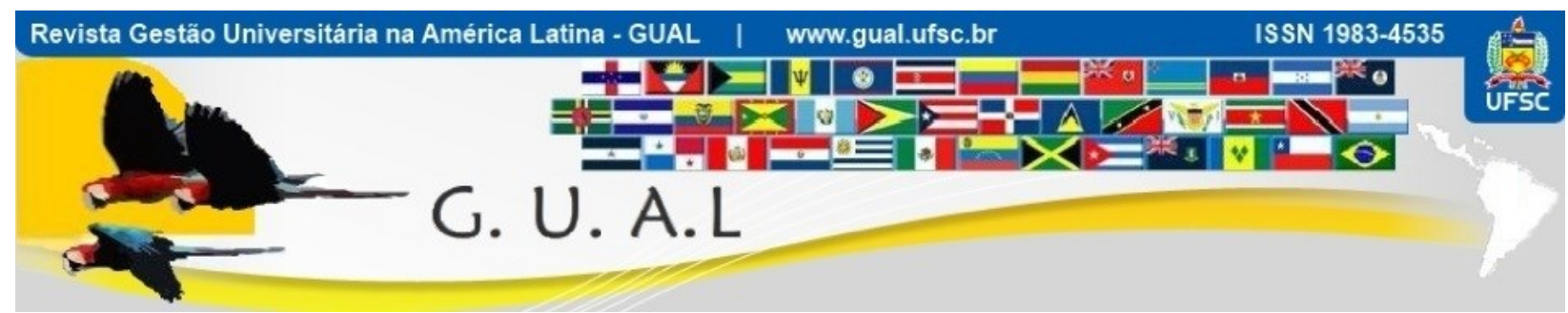

DOI: http://dx.doi.org/10.5007/1983-4535.2019v12n1p183

\title{
A VALIDADE PREDITIVA DO DESEMPENHO ACADÉMICO NO PRIMEIRO ANO PARA A PERFORMANCE FINAL NO ENSINO SUPERIOR
}

\section{PREDICTIVE VALIDITY OF THE ACADEMIC PERFORMANCE ON THE FIRST YEAR TO FINAL PERFORMANCE IN HIGHER EDUCATION}

Ruy Tadeu Mambrini Ribas, Mestre https://orcid.org/0000-0002-7406-8978 rtmribas@gmail.com

Universidade Federal de Santa Catarina | Programa de Pós-Graduação em Administração Florianópolis | SC | Brasil

Alexandre Marino Costa, Doutor https://orcid.org/0000-0003-1847-6026 marinocad@gmail.com Universidade Federal de Santa Catarina | Programas de Pós-Graduação em Administração Universitária | Programa de Pós-Graduação em Administração | Departamento de Ciências da Administração Florianópolis | SC | Brasil

Recebido em 25/abril/2017

Aprovado em 29/outubro/2018

Publicado em: 02/janeiro/2019

Sistema de Avaliação: Double Blind Review

Esta obra está sob uma Licença Creative Commons Atribuição-Uso. 


\title{
RESUMO
}

O presente estudo procura verificar a relação entre os indicadores de desempenho ao final do primeiro ano do ensino superior e aqueles que resumem a performance final, quando da conclusão do Curso para os mesmos sujeitos. O que se quer, portanto, é verificar a validade preditiva que aquela variável tem para esta segunda. A intenção do estudo que se coaduna com tal objetivo surge da preocupação com a descoberta de indicadores que permitam um diagnóstico antecipado das tendências de desempenho acadêmico, permitindo, assim, atuação da Administração Universitária no sentido de intervir com ações de gestão acadêmica mais ativa para tratar dos casos tempestivamente. Para a realização da análise foi feito estudo de caso incidente sobre os dados dos ingressantes nos Cursos de Administração, Direito e Pedagogia de uma Universidade Federal no ano de 2009. Após coleta das informações de performance acadêmica dos sujeitos, operações para verificação de correlação foram feitas entre o desempenho na conclusão do primeiro ano e na conclusão do Curso para verificar se aquele fator antecipa este. O estudo de caso quali-quantitativo, com ênfase na segunda componente do título metodológico, identificou que em todos os recortes existe forte correlação (resultados de $r$ variando entre 0.7 e 0.9 ) entre as variáveis, apontando que - ao menos para os casos em análise - o desempenho no primeiro ano seria forte preditor da tendência de desempenho global dos estudantes.

Palavras-chave: Avaliação. Validade Preditiva. Desempenho Acadêmico. Gestão Acadêmica. Administração Universitária.

\begin{abstract}
This study seeks to verify the correlation between indicators of academic performance in the first year of higher education and those of the graduation for the same individuals. The intention is to verify the predictive validity of the first variable in relation to the second one. The research arises from the concern and will to find indicators that allows an early diagnosis of the academic performance tendencies, creating opportunity for an tempestive action or intervention in certain specif cases or even broader scenarios. The analisys was made thru a case study of the 2009 classes of Administration, Law and Pedagogy Degrees of a brazilian Federal University. After gathering academic performance data of the subjects tests were made to verify the correletion between variables of performance at the conlusion of first year and at graduation time. The quali-quantitative research identified strong correlation ( $\mathrm{r}$ results between 0.7 and 0.9 ) between the variables pointing that - at least in the cases studied - the performance of first year was a strong predictor of the final performance in higher education.
\end{abstract}

Keywords: Evaluation. Predictive validity. Academic performance. Academic Management. University Administration. 


\section{A VALIDADE PREDITIVA DO DESEMPENHO ACADÊMICO NO PRIMEIRO ANO PARA A

\section{INTRODUÇÃO}

Importante ponto da gestão acadêmica de uma instituição de ensino superior - a bem da verdade, como de qualquer unidade educacional - é o acompanhamento do desempenho de seus estudantes ao longo do ciclo formativo, sobretudo para os atores e setores da gestão universitária diretamente envolvidos com o processo de ensino-aprendizagem e seus diversos reflexos para ambos estudantes e instituição.

Quer dizer, no âmbito institucional a preocupação e o acompanhamento próximo do tema poderá apontar indicativos (ou mesmo, conforme técnicas adotadas, verdadeiro indicados) do sucesso (ou falha) nas práticas de ensino-aprendizagem pelo bom (ou não) desempenho acadêmico de seus estudantes como um todo, em certas áreas do conhecimento ou acerca do desenvolvimento dos estudantes de determinado curso; do aproveitamento que os discentes apresentam em relação a uma grade curricular, um programa de ensino, à didática ou técnicas pedagógicas específicas e em diante.

Em suma, o que se aventa é a possibilidade de acompanhamento do sucesso de um projeto pedagógico ou outros itens de interesse da área de gestão acadêmica de uma instituição a partir do acompanhamento mais individualizado e cuidadoso do desempenho dos discentes conforme um critério de interesse; é a oportunidade da informação das decisões e tomada de ação - sejam administrativas ou pedagógicas - pelo subsídio dos resultados indicativos que se possa obter pelo monitoramento do desempenho estudantil de cada acadêmico ao longo de um ciclo formativo ou mesmo de um grupo, uma turma, em período igualmente selecionado ou de interesse. O que se argumenta é que este tipo de processo pode servir de importante apoio para diagnósticos e intervenções - mais ou menos pontuais e limitadas - conforme as prescrições que se mostrem necessárias das evidências colhidas.

É sobre o último item elencado que o presente artigo trata, tomando em mente preocupações com o acompanhamento do desempenho acadêmico do corpo discente de forma individualizada e progressiva para que seja possível, por exemplo, a identificação de talentos destacáveis ou de estudantes que encontrem (de forma efetiva ou potencial) dificuldades escolares no ensino superior permitindo atuação ou intervenção da instituição de forma tempestiva em cada caso.

Fala-se em tempestividade pois este é outro fator caro em nosso rol de preocupações, o temporal. Quando se menciona a busca de indicadores que possibilitem ação tempestiva o que se quer trazer à discussão é que estudantes de notável potencial podem tirar bom proveito de 


\section{A VALIDADE PREDITIVA DO DESEMPENHO ACADÊMICO NO PRIMEIRO ANO PARA A \\ DOI: http://dx.doi.org/10.5007/1983-4535.2019v12n1p183}

uma instituição que, ao tomar notícia de tanto, seja capaz, eventualmente, de subsidiá-los de maneira distinta apoiando a potencialidade. Por contraste (e não menos importante) dificuldades acadêmicas também devem ser percebidas em tempo de serem tratadas, antes que se consolidem, por exemplo, ou mesmo, no limite, imediatamente quando notadas para que ações voltadas ao problema sejam efetivas, eficazes.

Explica-se: quando potencial não exercido transforma-se em desinteresse e desmotivação ou quando dificuldades e baixo desempenho já repercutiram em evasão, seja por desistência, trancamento ou cancelamento voluntário de matrícula pelo estudante ou de ofício por mãos da instituição pela passagem de tempo limite para integralização curricular é tarde para que a gestão universitária e, especificamente a gestão acadêmica de uma instituição atue na retenção do acadêmico em seus bancos. De outra forma mas em sentido similar, mesmo que o estudante logre êxito em concluir o curso, pode ser situação de que o faça com baixo aproveitamento, alcançando os patamares mínimos para titulação mas com baixo desempenho ao longo de toda trajetória acadêmica. Em qualquer dos cenários o risco é o de percepção tardia de casos que, assim, serão perdidos pela omissão institucional e, neste ponto, nada (ou muito pouco) pode ser feito para revertes ou remediar as consequências.

Nesta toada, a questão fundamental, então, é a de diagnosticar, tão cedo seja possível, casos que demonstrem tendência ao baixo desempenho - por qualquer razão que seja, e este não será o objeto do estudo que aqui se faz - para que ações de apoio ou reforço pedagógico, por exemplo (ou outras que se provem necessárias em investigações de outra natureza) sejam implementadas; para que as instâncias com a finalidade de garantir permanência, retenção e sucesso acadêmico (e, por contrastes, evitar retenção e evasão) sejam acionadas à atuação antes que uma trajetória errática se consolide, como argumentado, repercutindo em consequências negativas ao estudante e à Instituição como todo.

Com tais reflexões em pauta que se desenha o presente estudo que quer verificar a possibilidade de predição do desempenho global de um estudante a partir dos resultados que alcança logo no início de seu ciclo formativo no ensino superior. A hipótese de trabalho é, portanto, a de que é possível diagnosticar a tendência do desempenho acadêmico de um estudante no ensino superior com base no desempenho inicial que apresenta quando ingressa em seu curso de escolha.

É, por tanto, que o objetivo do artigo que se lança adiante é o de verificar a validade preditiva do desempenho do primeiro ano do ensino superior de um estudante para o 


\section{A VALIDADE PREDITIVA DO DESEMPENHO ACADÊMICO NO PRIMEIRO ANO PARA A \\ DOI: http://dx.doi.org/10.5007/1983-4535.2019v12n1p183}

desempenho global que tende a alcançar quando de sua conclusão. Posto em questão, a inquietação que move a pesquisa assim se resume: É possível predizer a performance acadêmica de um estudante no ensino superior pelo desempenho que apresenta até a conclusão do primeiro ano curricular de seu curso?

Meta larga, no entanto, que demanda recorte pela natureza e extensão do presente estudo. Assim, mais modesta - mas ainda assim relevante como ponto de partida para as discussões que inexistem na proposta levantada - será a incidência de aplicação da análise. $\mathrm{O}$ que se investigará para argumentação de hipóteses será a relação entre o desempenho acadêmico de estudantes ingressantes nos Cursos de Administração, Direito e Pedagogia de uma Universidade Federal no ano de 2009 no momento de integralização do primeiro ano curricular e ao final do Curso. Assim, o que se quer verificar é se há relacionamento entre as duas variáveis - o que indicaria que - ao menos nestes casos - teria disso possível antecipar tendências de bom ou mais desempenho acadêmico já no primeiro ano do ensino superior.

Havendo necessidade de justificar o recorte, o ano de ingresso foi selecionado por distar do presente momento o ponto máximo de permanência dos estudantes do curso de menor duração elencado (Administração) e superar o ponto médio entre os extremos mínimo e máximo do período previsto para integralização curricular dos ingressantes nas demais graduações (Direito e Pedagogia). Quer dizer, a seleção do ano foi feita de forma a permitir que fossem computados no estudo aqueles que levaram mais tempo que o mínimo (e mesmo mais que o médio, aproximando-se do máximo) para concluir o Curso escolhido. Assim, em que pese possa parecer demasiado distante o ano de ingresso - e os dados que serão tratados, portanto - apenas no tempo presente que todos aqueles ingressantes vão tendo suas situações encaminhadas definitivamente: seja a conclusão, o abandono ou desistência do Curso. A intenção é, portanto, tornar a análise o mais abrangente possível, sem exclusões arbitrárias de sujeitos - e portanto a necessidade de tomada de ano aparentemente distante para estudo.

Sobre a escolha dos Cursos sobre os quais se realiza o estudo também fácil é a justificação - o que se tem em mente é sua representatividade no cenário da educação superior brasileira. É que para o ano de 2009 (e diferente não é o dado passada quase uma década) são aqueles os Cursos de Graduação com maior número de ingressantes, matrículas ativas e concluintes. Focando-se no argumento do número de matriculados, no ano de 2009, a Graduação em Administração relacionava 11,9\% das matrículas no ensino superior brasileiro, seguida pela Graduação em Direito, com 10,9\% e Pedagogia, com 8,6\%. O agregado dos três 


\section{A VALIDADE PREDITIVA DO DESEMPENHO ACADÊMICO NO PRIMEIRO ANO PARA A \\ DOI: http://dx.doi.org/10.5007/1983-4535.2019v12n1p183}

Cursos corresponde a quase um terço da educação de nível terciário no Brasil $(31,5 \%)$ e são seguidas de longe por outras carreiras que quando acrescentadas ao estudo pouco aumentam a representatividade do conjunto (a título informativo, a inclusão do quarto Curso em matrículas, Ciências Contábeis, repercutiria aumento de apenas 3,9\%; o décimo, por sua vez, Sistemas de Informação, acrescentaria modestos 1,5\% das matrículas) (MEC, 2016).

Finalmente, a Instituição selecionada para a análise assim o foi pela disponibilidade dos dados necessários para a realização das operações necessárias. Por razões éticas, no entanto, não haverá menção explícita ou identificação, bastando referência de que se trata de uma Universidade Federal brasileira.

Em encerramento deste prelúdio, então, o que efetivamente se objetiva com o estudo seguinte é verificar a correlação entre o desempenho acadêmico dos integrantes do grupo selecionado e justificado - qual seja, dos ingressantes no ano de 2009 nos Cursos de Graduação em Administração, Direito e Pedagogia em uma Universidade Federal - (a) ao final do primeiro ano curricular e (b) no momento da conclusão do Curso, com fins de verificar se, ao menos nestes casos específicos, aquele fator é fator preditivo deste, o que indicaria a possibilidade de seu uso como sólido item de acompanhamento dos gestores acadêmicos para identificação em período inicial do ciclo formativo dos estudantes com tendência a maior ou menor desempenho, permitindo intervenção tempestiva de gestores acadêmicos em cada caso.

\section{ACOMPANHAMENTO DO DESEMPENHO ACADÊMICO E SUA IMPORTÂNCIA}

O acompanhamento do desempenho acadêmico é tema que vai ganhando espaço na pauta de gestores universitários, sobretudo para atores e instâncias incumbidos do gerenciamento das áreas afeitas ao sucesso do processo de ensino-aprendizagem. É que fica evidente a conexão do tema com uma série de desafios que se colocam às instituições de ensino superior e seus gestores e, no item específico, com a necessária preocupação destes em relação ao desenvolvimento integral das potencialidades do corpo discente cumprindo a função que tem em relação a estes beneficiários imediatos e à sociedade em geral (SANTOS, 2000).

No outro polo argumentativo sobre a mesma preocupação, Mezzari e demais autores (2013) asseveram que a evasão tem se tornado, mais e mais, preocupação presente para os responsáveis por instituições de ensino vez que a ocorrência de casos em que um estudante 


\section{A VALIDADE PREDITIVA DO DESEMPENHO ACADÊMICO NO PRIMEIRO ANO PARA A PERFORMANCE FINAL NO ENSINO SUPERIOR \\ DOI: http://dx.doi.org/10.5007/1983-4535.2019v12n1p183}

inicia mas não chega ao final do Curso gera desperdícios de toda sorte, dos quais destacam aqueles de cunho social - com a perda, pela comunidade, de um profissional que seria potencialmente bem qualificado -; acadêmico - com a perda, pela universidade, de um egresso capacitado e de um contribuinte para o avanço da ciência em suas colunas -; e econômico - com os investimentos realizados em favor de um estudante que abandonou a vaga deixando-a, muitas vezes, ociosa ou subaproveitada.

Neste sentido, alguns são os estudos que conectam reprovações ou baixo desempenho acadêmico com desistência declarada, exclusão por abandono tácito ou qualquer outra classe de evasão pela ruptura marcada do vínculo com o Curso ou com seu enfraquecimento até que se extinga com o passar de algum tempo. Assim, em que pese as causas de evasão ou desempenho deficitário ao longo de um ciclo formativo no ensino superior sejam variadas e dificilmente resumidas em apenas um item, são vários os autores que identificam no baixo desempenho ou em reprovações iniciais fatores determinantes numa trajetória acadêmica precária ou de tendência decadente (BARDAGI; HUTZ, 2009).

É claro que, como argumentado, são diversas as razões possíveis para baixo aproveitamento ou abandono do ensino superior. A própria etapa de vida experimentada pela maioria dos ingressantes nas universidades e a transição dos níveis anteriores de escolarização para aquela de caráter superior já são fatores críticos. No mais, a necessária adaptação ao novo contexto e integração ao novo ambiente apresentam-se como desafios suficientemente destacáveis. (FREITAS; RAPOSO; ALMEIDA, 2007; COCHRANE, 1991).

Aqui, embora variados sejam os estudos desenvolvidos acerca de temas relacionados com a avaliação da educação superior e, neste contexto, do desempenho acadêmico - e em muitas das vezes com relação à evasão discente (DAVOK; BERNARD, 2016; TRESOLDI et al, 2015) - os gestores ainda carecem de diagnósticos prontos ou, ao menos, indicadores consistentes, informações ou ferramentas sólidas, que permitam uma administração acadêmica mais ativa, capaz de antecipar os problemas e neles agir de pronto, sem que ocorra o agravamento de situações contornáveis se endereçadas tempestivamente.

É que explicar desempenho acadêmico é tarefa complexa visto que muitos e amplos fatores e indicadores podem ser tomados em conta na busca por respostas (ARAUJO; CAMARGOS; CAMARGOS, 2011), notadamente variáveis de natureza acadêmica combinadas com outras demográficas ou econômicas (ANDRADE, 2005) ou analisadas em conjunto com outros itens que expressem o outro extremo da relação de ensino-aprendizagem, 


\section{A VALIDADE PREDITIVA DO DESEMPENHO ACADÊMICO NO PRIMEIRO ANO PARA A

quer dizer, variáveis referentes à qualificação do corpo docente ou o uso de recursos educacionais específicos, por exemplo (CRUZ; CORRAR; SLOMSKI, 2008).

Verificar tantas possibilidades de variáveis, no entanto, demandaria amplo volume e disponibilidade de dados e, no mais das vezes, sofisticados procedimentos estatísticos. Ainda, há o problema da própria coleta ou obtenção de tal sorte de dados e de sua confiabilidade. A interpretação dos resultados de tais testes, também, nem sempre seria clara ou acessível, de fácil compreensão, e a percepção de tendências ou estimativas poderia tornar-se igualmente desafiadora (COTTA, 2001) prejudicando a qualidade das conclusões ou mesmo inviabilizando a chegada em finais sólidos o suficiente para que se pudessem pretender conclusivos.

Estudos realizados em solo português, não obstante, foram capazes de apontar que a etapa de transição para o ensino superior e, aqui, principalmente o ajustamento acadêmico inicial é fator de maior relevância nas futuras realizações acadêmicas de um indivíduo (CUNHA; CARRILHO, 2005). Mais que isso, em verdade, pesquisas asseveram que o primeiro ano não é só fator importante, mas verdadeiramente determinante do restante da trajetória. Neste sentido que Ferreira, Almeida e Soares (2001) puderam concluir que o sucesso acadêmico como um todo está intimamente relacionado à experiência do primeiro ano de curso e o desempenho alcançado neste início do ciclo formativo superior.

Apresenta-se, então, uma hipótese de que (dentre outros itens que se poderia argumentar, é claro) ao menos o desempenho obtido no primeiro ano é fator crítico para a performance global de um estudante no ensino superior.

Uma vez que se tomou como verdade que é fundamental diagnosticar antecipadamente o perfil dos ingressantes no ensino superior, identificando potencialidades e fragilidades, acessando competências e habilidades (ou a falta de tantas) em tempo de que se possa atuar no sentido de prevenir trajetórias descendentes ou problemáticas, evasão e retenção, ou apoiar o desenvolvimento específico de determinados estudantes e neste sentido é a defesa de Dos Santos e Primi (2003) parece aqui surgir uma alternativa de indicador que pode se provar consistente e confiável na prestação de subsídios e informação a uma gestão acadêmica preocupada em atuar tempestivamente.

É diante deste cenário que vale explorar a capacidade ou validade preditiva destes dados mais acessíveis e que demandam menor tratamento estatítsico, quais sejam, dos resultados acadêmicos do primeiro ano de um estudante, pois podem, eventualmente, possuir 


\section{A VALIDADE PREDITIVA DO DESEMPENHO ACADÊMICO NO PRIMEIRO ANO PARA A \\ DOI: http://dx.doi.org/10.5007/1983-4535.2019v12n1p183}

alta correlação com os parâmetros que se queira antecipar para que o processo, finalmente, possa subsidiar a atuação do gestor universitário que se depare com desafios na administração acadêmica em uma instituição de ensino superior.

Em outras palavras, vale testar a hipótese de que os indicadores de desempenho do primeiro ano são capazes de antecipar a tendência do desempenho global; de que possuem validade preditiva em relação a esta performance global. Nesta toada, portanto, que vale, antes de seguir na verificação do indicador e suas possibilidades, esclarecer, com brevidade, o que se tem por validade preditiva, qual a significação do termo no presente contexto.

\subsection{VALIDADE PREDITIVA E SUA APLICAÇÃO NA AVALIAÇÃO DO DESEMPENHO ACADÊMICO}

Silva (2006) ao tratar de indicadores de desempenho e voltados à verificação de realizações educacionais afirma que se alguma relação existir, ela sempre existirá em determinada dimensão, podendo ser, assim, mensurada. Tendo tanto em mente, a medida a ser tomada no presente estudo é a da validade preditiva, que é o atributo de existência de relação entre duas variáveis quando há distanciamento temporal entre a coleta de uma informação e a verificação de sua validade com relação a outra variável, que só mais tarde se consolida (PASQUALI, 2009).

Desta forma, a validade se refere ao nível com que a informação inicial é útil para inferências futuras. No caso da validade preditiva, o apelo é para a verificação da existência de um relacionamento substancial, relevante, entre os resultados obtidos, no caso deste estudo, entre o desempenho acadêmico de um primeiro momento e o alcançado posteriormente conforme critério externo pertinente (SIMÕES, 2005). Em outros termos e especificamente no campo educacional - como é o caso da situação em tela - a validade preditiva será definida pela relação entre a pontuação em um momento e a performance posterior, futura, de um mesmo estudante conforme critérios estabelecidos como válidos para mensurar dito desempenho em um e outro ponto desta linha temporal (SANTROCK, 2011).

A determinação da validade preditiva, desta feita, se dá, no caso, pela análise de correlações e determinações em equações de regressão que testam a interação entre as variáveis numéricas que expressam (a) o desempenho obtido quando da conclusão do primeiro ano do Curso de Graduação e (b) o desempenho global do mesmo sujeito quando do término do ensino superior, quando da integralização curricular de seu Curso. O grau de 


\section{A VALIDADE PREDITIVA DO DESEMPENHO ACADÊMICO NO PRIMEIRO ANO PARA A \\ DOI: http://dx.doi.org/10.5007/1983-4535.2019v12n1p183}

relação entre estas variáveis é que determina a validade preditiva de uma (a) em relação à outra (b) (SILVA; MACEDO; SILVA, 2013).

\section{METODOLOGIA}

Após passagem pelo conceito de validade preditiva e compreendida a relevância deste aspecto, na medida em que é atributo dos testes que são capazes de traçar correlação entre desempenho obtido, um parâmetro antecedente, e performance posterior, pela existência de correlação de certa intensidade entre as variáveis, a verificação que se realizará persegue esta meta já declarada.

Assim, para a realização deste estudo, consulta aos registros do sistema de gestão das informações acadêmicas de uma Universidade Federal brasileira foi conduzida com fins de identificação de todos os ingressantes nos Cursos de Graduação em Administração, Direito e Pedagogia do ano de 2009 na instituição em comento. Individualizados os ingressantes - e preservada a identidade de cada um deles, realizando-se toda a pesquisa e posterior tratamento de dados sem identificação específica do perfil de qualquer destes estudantes sobre os quais incidiu o estudo - procedeu-se em consulta aos dados acadêmicos de cada um deles ao longo da trajetória acadêmica que percorreram.

Cumpre, então, explicitar os procedimentos metodológicos pelos quais foi possível conduzir a análise proposta. Inicialmente, como se faz relação aos Cursos de Graduação em Administração, Direito e Pedagogia em sentido amplo, há que se destacar que para os dois primeiros casos, a rigor, são dois os cursos - diurno e noturno. Os estudantes egressos de ambos ciclos fazem jus à mesma titulação, de bacharel em Administração e Direito, respectivamente, mas conforme a organização da Instituição em análise mais que turmas distintas, são Cursos distintos. Assim se faz em consideração a algumas variações menores nos currículos encarados por cada grupo. A diferença mais se dá, no entanto, na distribuição de algumas disciplinas ao longo do tempo na grade, sem alterações das matérias encaradas no primeiro ano ou quando da integralização.

Desta forma, para os fins deste estudo, a eventual diferença curricular não impacta nos indicadores selecionados para análise de correlação e os mais variados recortes podem ser feitos sem prejuízo à solidez dos dados. O estudo, assim, é incidente sobre 5 grupos - os ingressantes dos dois Cursos de Administração (diurno e noturno), dos dois Cursos de Direito (diurno e noturno) e do Curso de Pedagogia. 


\section{A VALIDADE PREDITIVA DO DESEMPENHO ACADÊMICO NO PRIMEIRO ANO PARA A \\ DOI: http://dx.doi.org/10.5007/1983-4535.2019v12n1p183}

Ainda em relação à população do estudo, o ponto de partida é, portanto, a lista de ingressantes no ano de 2009 para os cursos de Administração Diurno (100 sujeitos); Administração Noturno (100 Sujeitos); Direito Diurno (90 sujeitos); Direito Noturno (90 Sujeitos) e Pedagogia (100 sujeitos) - um total de 480 indivíduos.

Destes numerais a busca por correlações poderá incidir sobre aqueles que tenham alcançado a conclusão de seus Cursos até dezembro de 2017, tempo em que foram coletadas as informações de desempenho final. Os casos em que se verificou interrupção interveniente do vínculo (por abandono, desistência, jubilamento ou qualquer outra razão) foram excluídos dos resultados, por óbvio, pela inocorrência de conclusão do Curso, e assim, inexistência de dados para a performance final.

Assim se fez para garantir que a seleção representa a totalidade dos possíveis "participantes" da análise proposta. Trata-se de critério autoral, como explicitado, encontrando sustentação no conceito de amostragem dita não-probabilística por Gil (2008).

Quer dizer, a escolha da amostra frente ao eventual universo foi realizada por tipicidade, já que os sujeitos são selecionados por sua representatividade, que neste caso, é total frente à população-alvo, em análise de perspectiva transversal, realizando recorte específico na linha do tempo e estudando-o pormenorizadamente (VERGARA, 2013).

Aqui ponto importante: em que pese o exaurimento da população selecionada e assim a plena confiabilidade dos resultados para o grupo selecionado, não se pretende com tais dados extrapolar as margens do estudo por alguma operação probabilística, mas sim, em troca, poder fazer conclusões irrestritas mesmo que sobre o grupo limitado analisado.

Os Cursos escolhidos, como exposto em etapa inicial do presente escrito, assim o foram pela representatividade das carreiras no ensino superior brasileiro tanto no tempo de ingresso dos sujeitos estudados e, assim, dos dados iniciais, referentes ao desempenho no primeiro ano do ensino superior como no presente, em que se colhe a performance final e se procede às análises (MEC, 2016).

Os parâmetros utilizados para a medição foram o Índice de Aproveitamento Acumulado (IAA) ao final do primeiro ano e no momento da integralização curricular do Curso, de sua conclusão, portanto. Assim, é possível verificar a existência (ou não) de relação entre o desempenho quando do término do primeiro ano e do curso como um todo, verificando se aquele escore é preditor deste último, atestando a hipótese aventada de que seria ferramenta importante para intervenções tempestivas da gestão acadêmica. 


\section{A VALIDADE PREDITIVA DO DESEMPENHO ACADÊMICO NO PRIMEIRO ANO PARA A PERFORMANCE FINAL NO ENSINO SUPERIOR \\ DOI: http://dx.doi.org/10.5007/1983-4535.2019v12n1p183}

Vale esclarecer que o Índice de Aproveitamento Acumulado (IAA) - que é o indicador de desempenho acadêmico oficialmente utilizado pela Instituição em estudo - expressa a somatória do produto da nota obtida em cada disciplina pela carga horária referente a cada uma delas tudo, finalmente, dividido, também proporcionalmente, por toda a carga horária cursada pregressamente, retornando o desempenho global de um estudante até determinado ponto de sua trajetória acadêmica. Pelo balanceamento do Índice ao longo do tempo é ele mesmo que tem que ser usado no estudo vez que não sofrerá distorções indevidas pelo decurso temporal.

Materialmente, a pesquisa foi feita calculando-se, com uso do MS Excel, a correlação (Coeficiente de Correlação de Pearson $-r$ ou $\rho$ ) entre as variáveis " $x$ " (IAA de conclusão do primeiro ano do Curso) e "y" (IAA de conclusão do Curso). Cabe, já aqui, a anotação de que o número resultante nesta operação é sempre contido no intervalo entre -1 e 1 , casos extremos em que resta demonstrada a plena correlação negativa ou positiva; sendo o centro deste espectro, o resultado 0 que, por sua vez, representa inexistência de correlação entre as variáveis confrontadas. Ainda, calculou-se, com suporte do mesmo software, o Coeficiente de determinação de regressões lineares $\left(\mathrm{R}^{2}\right)$ que, variando entre 0 e 1 , aponta em que percentual o modelo linear explica a evolução relacionada dos valores, se ajusta a evolução contínua das variáveis. (MUKAKA, 2012; HINKLE, WIERSMA, JURS, 2003).

Ainda, em relação à classificação da pesquisa, tem-se que, quantos aos fins, trata-se de um estudo descritivo já que se ocupa de explicitar características de uma população selecionada, não necessariamente explicando plenamente os fenômenos descritos mas com análise que serve de base para eventuais explicações (VERGARA, 2013). Quanto aos meios, a pesquisa enquadra-se como um "estudo de caso" pois intenciona, com base nas informações levantadas e analisadas, classificar as comunidades específicas estudadas entre determinados tipos ideais suficientemente conhecidos (GIL, 1991).

Exatamente estas são as intenções do estudo: a partir dos coeficientes obtidos em operações matemáticas, classificar os resultados, e portanto, as comunidades que a eles deram origem, nos estratos estabelecidos pela literatura que, com exaustivo estudo da questão, estipula valores para cada um dos "tipos ideais" mencionados.

Finalmente, ainda em relação à metodologia, o estudo se serve da advertência de Bryman (2012) que trata da impossibilidade de se querer classificar uma pesquisa como puramente quantitativa ou qualitativa, podendo haver no máximo uma aproximação maior ou 


\section{A VALIDADE PREDITIVA DO DESEMPENHO ACADÊMICO NO PRIMEIRO ANO PARA A PERFORMANCE FINAL NO ENSINO SUPERIOR \\ DOI: http://dx.doi.org/10.5007/1983-4535.2019v12n1p183}

menor com determinados elementos de um ou outro "extremo" da tipologia metodológica. Assim, há que se classificar a presente pesquisa como uma de concepção "quali-quantitativa", por congregar traços compartilhados e transitar por linhas típicas de ambos os campos (MARCONI; LAKATOS, 2007). É verdade que a opção por etapa aplicada baseada na redução do fenômeno social por indicadores objetivos, numerais, mostra um fundo quantitativo, a própria intenção de mais verificar tal fenômeno (ou não) que buscar explicações de sua essência é característica notadamente quantitativa da pesquisa. Por outro lado, tais medidas numeradas não se constituem, aqui, em fins próprios, mas "integram um processo de descrição, predição, diagnóstico [diante de um fenômeno social]" e daí não parecer cabível falar que se trata de mero e puro estudo quantitativo, mas, sim, no máximo, com ênfase nesta raiz científica (PEDHAZUR; SCHMELKIN, 1991, p. 15).

\section{RESULTADOS E DISCUSSÃO}

Expostas as razões de motivação do presente estudo, sua base teórica e a hipótese que pretende explorar e também explicados os procedimentos metodológicos pelos quais a etapa aplicada de pesquisa se realizou, parte-se à dissertação acerca dos resultados obtidos nas operações feitas e a discussão de seus significados que podem informar conclusões posteriores na etapa de encerramento do presente escrito.

\subsection{OPERAÇÕES E RESULTADOS OBTIDOS}

O primeiro grupo analisado foi aquele constituído pelos estudantes do Curso de Administração Diurno. Dos 100 sujeitos que iniciaram o ciclo formativo no ano de 2009 apenas 58 o haviam concluído até dezembro de 2017. Os outros 42 abandonaram tacitamente o Curso, desistiram explicitamente, buscaram transferências ou tiveram o vínculo rompido por questões administrativas. Para o contingente que integralizou a malha curricular do Curso o coeficiente de correlação entre o desempenho do primeiro ano e o final foi de $0,836981(\mathrm{r}=$ 0.836981) com um modelo linear ajustando-se ao avanço contínuo das variáveis em aproximadamente $70 \%$ dos casos $\left(\mathrm{R}^{2}=0.700537\right)$, conforme gráfico: 
Gráfico 1 Correlação entre o desempenho do primeiro ano e o final dos estudantes do Curso de Administração Diurno ingressantes em 2009

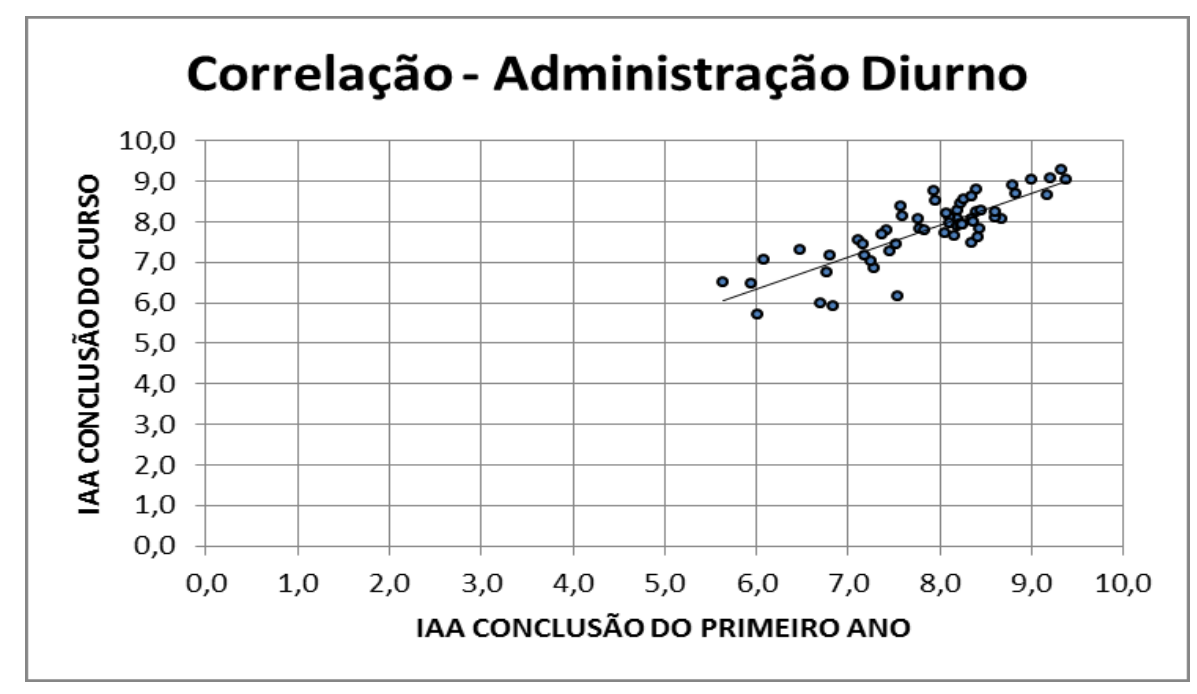

Fonte: Elaborado pelos autores (2018).

Tomados para análise os estudantes ingressantes no Curso de Administração Noturno, tem-se que dos 100 sujeitos teóricos iniciais, 40 acabaram por não levar ao final o Curso, razão pela qual o estudo foi incidente sobre os dados de desempenho dos 60 restantes que lograram a formatura. Para este grupo o coeficiente de correlação obtido da oposição das variáveis selecionadas foi de $0.704812(\mathrm{r}=0.704812)$ com ajuste de uma reta de tendência neste modelo em algo como metade dos casos $\left(R^{2}=0.496759\right)$. A representação de forma gráfica ajuda a visualizar os itens:

Gráfico 2 Correlação entre o desempenho do primeiro ano e o final dos estudantes do Curso de Administração Noturno ingressantes em 2009.

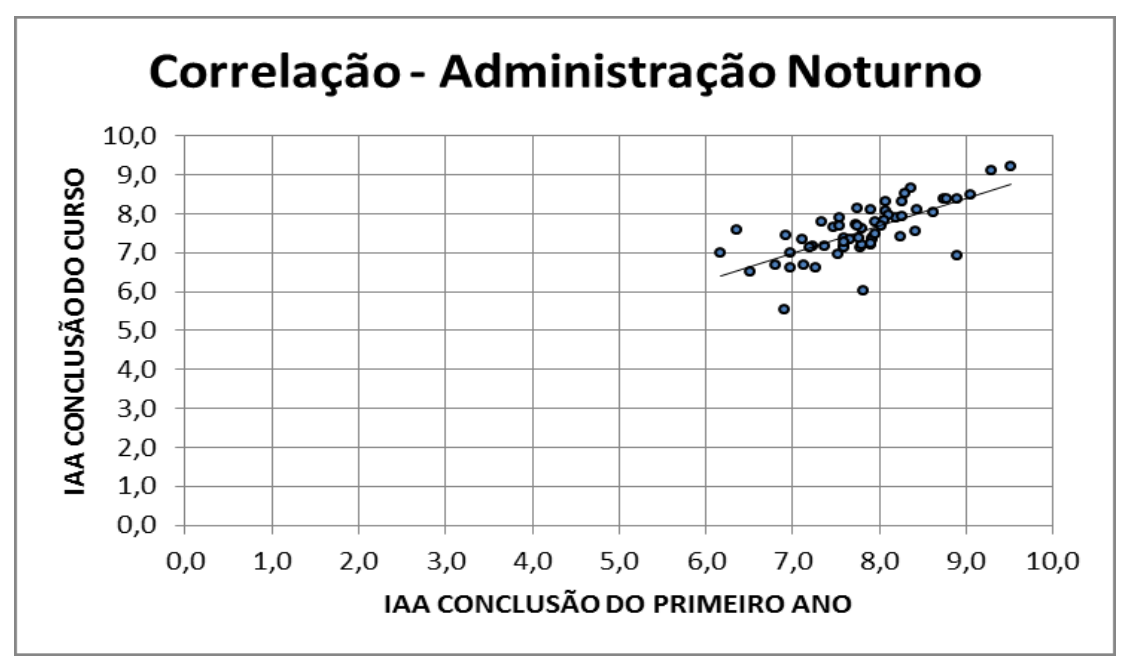

Fonte: Elaborado pelos autores (2018). 


\section{A VALIDADE PREDITIVA DO DESEMPENHO ACADÊMICO NO PRIMEIRO ANO PARA A PERFORMANCE FINAL NO ENSINO SUPERIOR \\ DOI: http://dx.doi.org/10.5007/1983-4535.2019v12n1p183}

Passando ao Curso de Graduação em Direito, quando se toma o grupo Diurno para análise, dos 90 ingressantes na origem, 74 levaram a formação até o final. Para este universo a correlação é resumida pelo índice de $0.924707(\mathrm{r}=0.924707)$ com o ajuste de um modelo linear de evolução das variáveis em mais de $85 \%$ dos casos $\left(\mathrm{R}^{2}=0.855083\right)$. Os resultados podem ser visualizados graficamente na plotagem seguinte:

Gráfico 3 Correlação entre o desempenho do primeiro ano e o final dos estudantes do Curso de Direito Diurno ingressantes em 2009

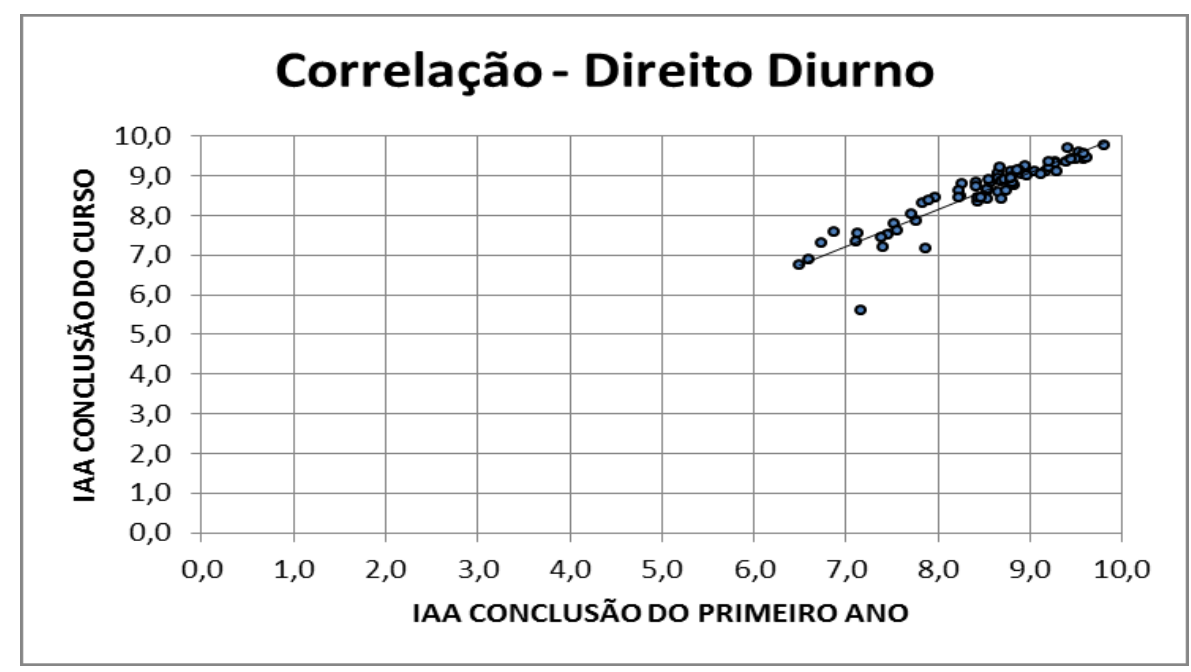

Fonte: Elaborado pelos autores (2018).

Quando realizado, o estudo, a partir dos dados obtidos em referência aos ingressantes no Curso de Direito noturno do ano e Instituição em comento, tem-se que para os 90 sujeitos iniciais 71 atravessaram o ciclo formativo sem interrupções por causas variadas, vindo a concluir o Curso até o término do ano de 2017. Para esta amostra o coeficiente de correlação encontrado entre as variáveis em comento foi $0.803919(\mathrm{r}=0.803919)$ com possibilidade de ajuste de uma reta para os pontos gráficos em aproximadamente $65 \%$ das situações $\left(\mathrm{R}^{2}=\right.$ 0.646286). O cenário específico é graficamente representado da maneira seguinte: 
Gráfico 4 Correlação entre o desempenho do primeiro ano e o final dos estudantes do Curso de Direito Noturno ingressantes em 2009

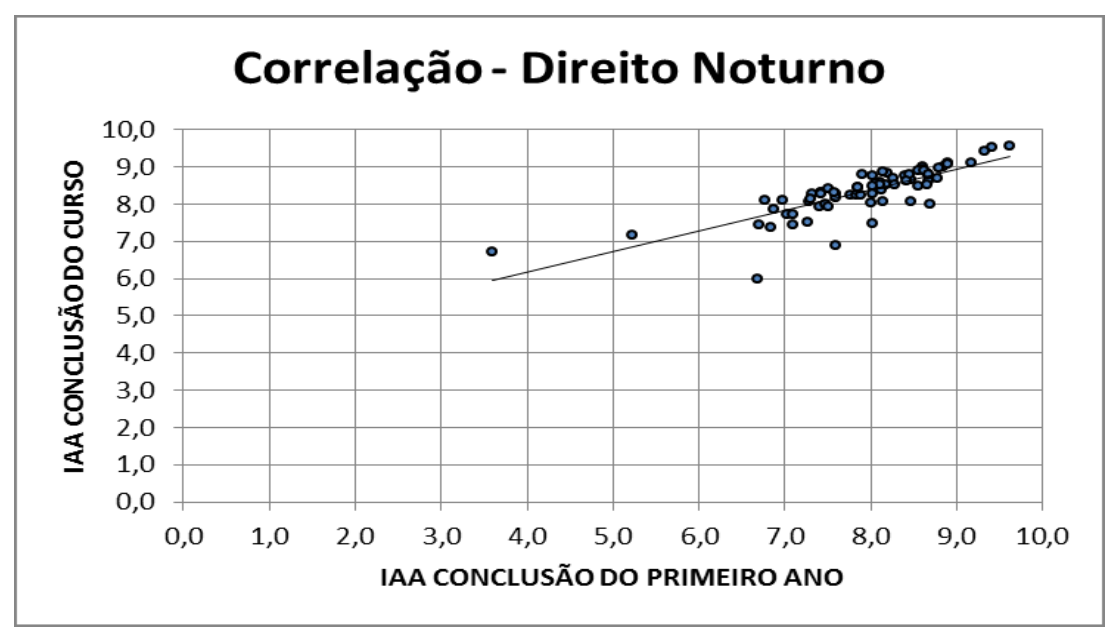

Fonte: Elaborado pelos autores (2018).

O último Curso em Análise, de Pedagogia, conta com o ingresso anual de 100 estudantes, não havendo multiplicidade de turnos e, assim, diferenciação de grupos. Deste total, foi possível perceber que 59 foram os sujeitos concluintes de dita graduação até o momento da tomada dos dados, o restante tendo abandonado os bancos do Curso ao longo do ciclo por variadas razões. Aqui, as operações quando feitas sobre tal público retornam coeficiente de correlação de $0.797703(\mathrm{r}=0.797703)$ com avanço linear dos pontos numa reta teórica em pouco mais de $63 \%$ dos casos $\left(\mathrm{R}^{2}=0.636330\right)$. A demonstração gráfica em dispersão permite visualizar:

Gráfico 5 Correlação entre o desempenho do primeiro ano e o final dos estudantes do Curso de Pedagogia ingressantes em 2009

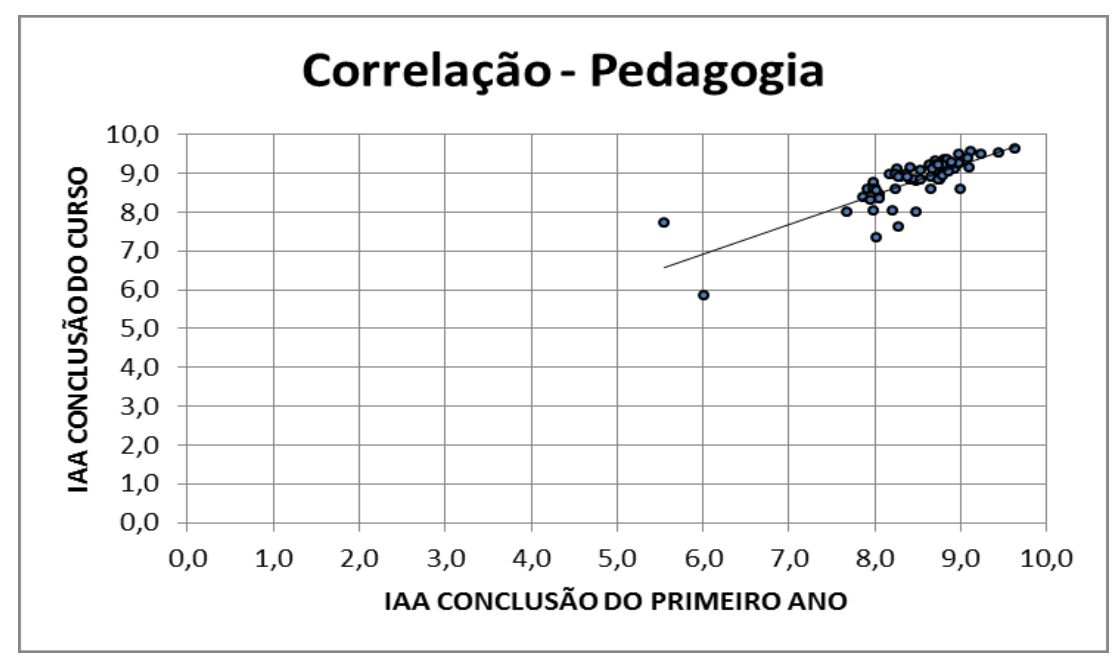

Fonte: Elaborado pelos autores (2018). 


\section{A VALIDADE PREDITIVA DO DESEMPENHO ACADÊMICO NO PRIMEIRO ANO PARA A PERFORMANCE FINAL NO ENSINO SUPERIOR \\ DOI: http://dx.doi.org/10.5007/1983-4535.2019v12n1p183}

Finalmente, analisados todos os grupos de maneira segmentada, como requer o rigor metodológico do bom estudo científico e, no caso concreto, e em observação às divisões técnicas e terminológicas da Instituição para a separação de seus Cursos, realizou-se exercício de contabilização de todos os sujeitos dos distintos grupos em uma mesma operação. Quer dizer, criou-se um grupo sintético, teórico, que representa o total dos estudantes passíveis de serem estudados no recorte mais amplo possível da presente análise. Assim se fez para que se pudesse cogitar de conclusões para a integralidade do grupo para além de cada um de seus segmentos menores.

Nesta derradeira análise, dos 480 sujeitos ingressantes iniciais nos Cursos aqui estudados, 322 foram os concluintes até o término do ano letivo de 2017. A operação de análise de correlação incidente sobre todo este universo retorna coeficiente de $0.809292(\mathrm{r}=$ $0.809292)$ com ajuste de um modelo linear em pouco mais de $65 \%$ das situações $\left(\mathrm{R}^{2}=\right.$ 0.654954). Para este conjunto o gráfico se dá conforme a plotagem que segue:

Gráfico 6 Correlação entre o desempenho do primeiro ano e o final dos estudantes dos Cursos de Administração Diurno e Noturno, Direito Diurno e Noturno e Pedagogia ingressantes em 2009

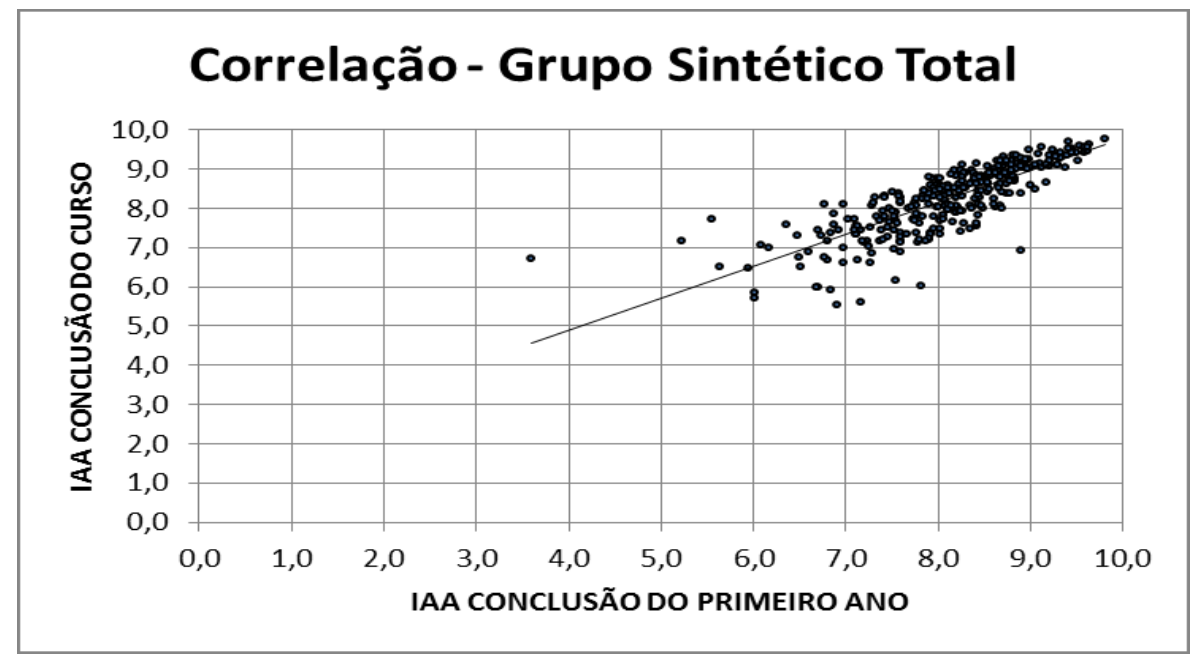

Fonte: Elaborado pelos autores (2018).

Pela multiplicidade de números apresentados e a extensão da seção que traz os resultados obtidos vale fazer resgate simplificado de tudo antes de partir para a análise de seus significados e a tomada de conclusões a partir de tanto. Assim sendo, organiza-se quadro de resumo de todo o encontrado: 


\section{A VALIDADE PREDITIVA DO DESEMPENHO ACADÊMICO NO PRIMEIRO ANO PARA A PERFORMANCE FINAL NO ENSINO SUPERIOR \\ DOI: http://dx.doi.org/10.5007/1983-4535.2019v12n1p183}

Quadro 1 Resumo dos estudos de Correlação

\begin{tabular}{|l|c|c|}
\hline \multicolumn{1}{|c|}{ Grupo } & Coeficiente de Correlação (r) & Coeficiente de Determinação (R $\left.\mathbf{R}^{\mathbf{2}}\right)$ \\
\hline Administração Diurno & 0,836981 & 0.700537 \\
\hline Administração Noturno & 0.704812 & 0.496759 \\
\hline Direito Diurno & 0.924707 & 0.855083 \\
\hline Direito Noturno & 0.803919 & 0.646286 \\
\hline Pedagogia & 0.797703 & 0.636330 \\
\hline Sintético Total & 0.809292 & 0.654954 \\
\hline
\end{tabular}

Fonte: Elaborado pelos autores (2018).

\subsection{DISCUSSÃO DOS RESULTADOS OBTIDOS}

É de posse de todos estes coeficientes encontrados em cada uma das incidências dos cálculos realizados que se pode tirar conclusões conforme a proposta e a metodologia definidas para este artigo. É que a partir de tais índices que se pode enquadrar os recortes feitos em um determinado "tipo ideal", procedimento próprio dos estudos de caso, feito sempre com base em um critério de referência, de definição destes ditos "tipos". Ainda, na busca por critérios de classificação entre os "tipos", há que se considerar a existência de pluralidade de valores e significados atribuídos por cada um dos autores que estabelecem regras de classificação para as hipóteses de correlação entre variáveis.

Nesta toada, Hatcher (2003) faz proposta de guia para interpretação da força de correlação entre duas variáveis com base no valor absoluto do coeficiente percebido, sendo o sinal (positivo ou negativo) indicativo da direção desta relação. Para o autor um coeficiente de .00 significa não haver relação; .20 relação fraca; .50 relação moderada; .80, relação forte; e 1.00 relação perfeita.

Hinkle, Wiersma e Jurs (2003), de outra forma, apresentam distinta escala de interpretação, em que coeficientes entre .00 e .30 representam correlação ínfima, se existente; entre .30 e .50 correlação existente mas baixa; entre .50 e .70 correlação existente e moderada; entre .70 e .90 correlação existente e alta; e entre .90 e 1.00 correlação existente e muito alta. Os sinais, diferente não poderia ser, também indicam se a relação é direta ou inversa.

Qualquer que seja o manual selecionado, é possível notar que oferecem interpretação bastante próxima dos valores, com faixas de classificação distintas mas de acordo com uma mesma lógica (e similaridade métrica, inclusive) de julgamento. É diante destes referenciais que se torna possível revisitar os índices obtidos como resultado das operações feitas e retirar significados dos numerais encontrados. 


\section{A VALIDADE PREDITIVA DO DESEMPENHO ACADÊMICO NO PRIMEIRO ANO PARA A PERFORMANCE FINAL NO ENSINO SUPERIOR \\ DOI: http://dx.doi.org/10.5007/1983-4535.2019v12n1p183}

O que se tem, então, é que, em todas incidências de estudo, a correlação entre o índice de desempenho acadêmico ao final do primeiro ano e no momento da conclusão do ensino superior é existente e, relevante, alta, forte. A mera revisão dos coeficientes, de posse dos referenciais supramencionados, permite tal interpretação e os gráficos possibilitam visualização ainda mais clara do diagnóstico independente do recurso aos coeficientes correlacionais.

Em suma, para cada um dos casos analisados e para a totalidade deles (resumida no grupo sintético criado) o desempenho do primeiro ano é dotado de validade preditiva em relação ao desempenho global. Em outras palavras, o desempenho na conclusão do primeiro ano do ensino superior - em larga medida - prevê a performance quando da conclusão do Curso pela alta correlação existente entre as variáveis.

\section{CONCLUSÃO}

Realizada a pesquisa e vistos seus resultados, resta provada a existência de forte correlação entre as variáveis estudadas, resumida pelos coeficientes de correlação encontrados (r) sempre elevados e acompanhados de numerais igualmente consideráveis para os coeficientes de determinação $\left(\mathrm{R}^{2}\right)$, que indica, ainda, a evolução mais ou menos linear do avanço contínuo entre as variáveis em relevante parcela dos casos.

Os achados deixam claro que - para os sujeitos estudados - o desempenho acadêmico do primeiro ano seria forte preditor da tendência e da consolidação da performance acadêmica que alcançariam ao término do curso. A análise dos pontos nos gráficos de dispersão mostra linearidade considerável na medição, conforme modelos desta natureza (CRESPO, 2009), deixando claro que as variáveis não apenas se relacionam, mas o fazem não ao acaso nem por modelos extremamente sofisticados. (GLASS; STANLEY, 1970; HOFFMANN; VIEIRA, 1987).

Pode-se afirmar, portanto, que o monitoramento dos resultados obtidos pelos estudantes ao término do primeiro ano de seus Cursos (para o cenário analisado) seria, se não suficiente - pela inexistência de relação perfeita $(r=1)$, a rigor, existente, de toda forma, nas ciências sociais, mais em abstrações teóricas que em casos concretos - extremamente relevante para antecipar o desempenho que alcançariam ao longo do Curso até o seu final.

Tal achado, é verdade, é restrito ao grupo sobre o qual incidiu a coleta e análise de dados. A análise feita, como se deixou claro, não tem intenções de extrapolar suas conclusões 


\section{A VALIDADE PREDITIVA DO DESEMPENHO ACADÊMICO NO PRIMEIRO ANO PARA A PERFORMANCE FINAL NO ENSINO SUPERIOR \\ DOI: http://dx.doi.org/10.5007/1983-4535.2019v12n1p183}

para universos maiores ou de, por si própria, criar enunciados gerais. De qualquer forma, há um indicativo de que, ao menos nos recortes representativos aqui feitos, o desempenho acadêmico inicial é forte preditor da performance futura e final. $\mathrm{O}$ achado vai no mesmo sentido das hipóteses levantadas a partir da revisão bibliográfica estrangeira e pode, assim, sugerir que - na realização de outros e mais abrangentes estudos neste sentido, alargando as margens de seu alcance pela ampliação da janela temporal ou do grupo de Cursos pesquisado - tal indicador possa ser incorporado em ferramentas, práticas, ações, da gestão acadêmica de uma Universidade, com fins de monitorar o desempenho estudantil, diagnosticar antecipadamente tendências e atuar tempestivamente no sentido de corrigir trajetórias erráticas por ações que recuperem desempenho e evitem evasão e retenção, por exemplo, ou fomentar e fortalecer as potencialidades daqueles que, desde cedo, demonstrem potencial para tendências de alta performance.

\section{REFERÊNCIAS}

ANDRADE, J. X. Condicionantes do desempenho dos estudantes de Contabilidade: evidências empíricas de natureza acadêmica, demográfica e econômica. In: ENANPAD, 29., 2005, Brasília (DF). Anais...Rio de Janeiro: ANPAD, 2005.

ARAUJO, Elisson Alberto Tavares; CAMARGOS, Marcos Antônio de; CAMARGOS, Mirela Castro Santos. Desempenho acadêmico dos discentes do Curso de Ciências Contábeis: uma análise dos seus fatores determinantes em uma IES privada. In: ENANPAD, 35., 2011, Rio de Janeiro (RJ). Anais... Rio de Janeiro: ANPAD, 2011.

BARDAGI, Marucia Patta; HUTZ, Cláudio Simon. "Não havia outra saída": percepções de alunos evadidos sobre o abandono do curso superior. PSICO-USF. V. 14, n.1, p. 95-105, janabr, 2009.

BRYMAN, Alan. Social research methods. Oxford, New York, England: Oxford University Press, 2012.

COCHRANE, C. First Year at university: a study of mature female students. Irish Journal of Education, 25, 42-51, 1991.

COTTA, T. C. Avaliação educacional e políticas públicas: a experiência do Sistema Nacional de Avaliação da Educação Básica (Saeb). Revista do Serviço Público (RSP), 52, n. 4, 2001. 89-111.

CRESPO, Antônio Arnot. Estatística fácil. 19. ed. atual. São Paulo: Saraiva, 2009. xi, 218 p CRUZ, C. V. O. A.; CORRAR, L. J.; SLOMSKI, V. Docência e o desempenho dos alunos dos cursos de graduação em Contabilidade no Brasil. Revista Contabilidade Vista e Revista, Belo Horizonte, v. 19, n. 4, p. 15-37, out. / dez. 2008. 
CUNHA, Simone Miguez; CARRILHO, Denise Madruga. O processo de adaptação ao ensino superior e o rendimento acadêmico. Psicologia Escolar e Educacional, Campinas (SP), v. 9, n. 2, p. 215-224, dez. 2005. Disponível em: <

pepsic.bvsalud.org/scielo.php?script $=$ sci_arttext\&pid=S1413-85572005000200004 $>$. Acesso em: 12 fev. 2018.

DAVOK, D. F.; BERNARD, R. P. Avaliação dos índices de evasão nos cursos de graduação da Universidade do Estado de Santa Catarina - UDESC. Avaliação (Campinas), Sorocaba, SP, v. 21, n. 2, p. 503-521, jul. 2016.

DOS SANTOS, Acácia Aparecida Angeli; PRIMI, Ricardo. Estudo das relações entre compreensão em leitura e desempenho acadêmico na universidade. Interação em Psicologia, Curitiba, v. 7, n. 1, p. 19-25, jun. 2003. Disponível em:

$<$ http://revistas.ufpr.br/psicologia/article/view/3203>. Acesso em: 06 fev. 2018.

FERREIRA, J.A.; ALMEIDA, L.S.; SOARES, A.P. Adaptação acadêmica em estudantes do $1^{\circ}$ ano: diferenças de gênero, situação de estudantes e cursos. Revista Psico- USF, 6, 1-10, 2001 .

FREITAS, Helena Cristina das Neves Mira; RAPOSO, Nicolau de AlmeidaVasconcelos; ALMEIDA, Leandro S. Adaptação do estudante ao ensino superior e rendimento académico: um estudo com estudantes do primeiro ano de enfermagem. Revista Portuguesa de Pedagogia. 41-1, p. 179-188, 2007. Disponível em: < http://impactum-

journals.uc.pt/rppedagogia/article/download/1191/639/>. Acesso em: 08 fev. 2018.

GIL, Antonio Carlos. Como elaborar projetos de pesquisa. 3a ed. São Paulo: Atlas, 1991. $159 \mathrm{p}$.

GIL, Antonio Carlos. Métodos e técnicas de pesquisa social. 6.ed. São Paulo: Atlas, 2008. XVI, 200p.

GLASS, Gene V.; STANLEY, Julian C. Metodos estadisticos aplicados a las ciencias sociales. Englewood Cliffs: Prentice Hall, c1970. xvi, 597p.

HATCHER, Larry. Step-by-step basic statistics using SAS: student guide. Cary: SAS Institute, 2003. X, 692p

HINKLE, Dennis E. WIERSMA, William. JURS, Stephen G. Applied statistics for the behavioral sciences. 5 th. ed. Boston: Houghton Mifflin, 2003.

HOFFMANN, Rodolfo; VIEIRA, Sonia. Analise de regressão: uma introdução a econometria. 2.ed. São Paulo: HUCITEC, 1987. 379p.

MEC - Ministério da Educação. Censo da Educação Superior: principais resultados, 2016. Disponível em: $<$ https://abmes.org.br/arquivos/documentos/censo_superior_tabelas.pdf $>$. Acesso em: 13 fev. 2018. 


\section{A VALIDADE PREDITIVA DO DESEMPENHO ACADÊMICO NO PRIMEIRO ANO PARA A PERFORMANCE FINAL NO ENSINO SUPERIOR \\ DOI: http://dx.doi.org/10.5007/1983-4535.2019v12n1p183}

MEZZARI, Adelina; et al. Estratégias para detecção precoce de propensão à evasão. Revista Iberoamericana de Educação a Distância. V. 16, n. 2, p. 147-175, 2013.

MUKAKA, M. A guide to appropriate use of correlation coefficient in medical research. Malawi Medical Journal, Malawi, v. 24, n. 3, p. 69-71, 2012. Disponível em: < https://www.ncbi.nlm.nih.gov/pmc/articles/PMC3576830/>. Acesso em: 23 jan. 2017.

PASQUALI, Luiz. Psicometria. Revista da Escola de Enfermagem da USP, São Paulo (SP), v. 43, dez. 2009. Disponível em: <

http://www.scielo.br/scielo.php?script=sci_arttext\&pid=S0080-62342009000500002>. Acesso em: 18 jan. 2018.

PEDHAZUR, Elazar J.; SCHMELKIN, Liora Pedhazur. Measurement, design, and analysis: an integrated approach. Hillsdale, New Jersey: Lawrence Erlbaum Associates, 1991.

SANTOS, L.T.M. dos. Vivências acadêmicas e rendimento escolar: estudo com alunos universitários do $1^{\circ}$ ano. 2000. Dissertação de Mestrado - Universidade do Minho, Braga, Portugal, 2000.

SANTROCK, John W. Educational Psichology. 5 ed. New York (NY): McGraw-Hill , 2011. $584 \mathrm{p}$.

SILVA, José Aparecido da. Se alguma coisa existe, ela existe em certa quandidade e pode ser mensurada: o valor preditivo dos Exames Vestibulares. São Paulo, 11 de julho de 2006.

Disponível em: < http://mesaredonda2.blogspot.com.br/2006/07/se-alguma-coisa-existe-elaexiste-em.html>. Acesso em: 20 dez. 2017.

SILVA, Roseane Patrícia Araújo; MACÊDO, Larissa Cristina Bazilio de; SILVA, Izabela Lorena Ribeiro da. Avaliação das características psicométricas dos questionários utilizados nos periódicos da área contábil: um estudo longitudinal compreendido no período 2003-2012. XX Congresso Brasileiro de Custos, Uberlândia (MG), nov. 2013. Disponível em:

$<$ https://anaiscbc.emnuvens.com.br/anais/article/viewFile/124/124>. Acesso em 15 jan. 2018.

SIMÕES, Mário R. Potencialidades e limites do uso de instrumentos no processo de avaliação psicológica. Psicologia, Educação e Cultura. Colégio Internato dos Carvalhos, Portugal, v. IX, dez. 2005, p. 237-263. Disponível em:

$<$ https://comum.rcaap.pt/bitstream/10400.26/5261/1/2005_PEC_2.pdf\#page=11>.Acesso em 17 jan. 2018.

TRESOLDI, T.; SIMÕES, L. J.; NABARRO, E.; POLIDORI, M. M. Análise de desempenho acadêmico de estudantes com ingresso por reserva de vagas na Universidade Federal do Rio Grande do Sul (UFRGS). In: SIMPÓSIO DE AVALIAÇÃO DA EDUCAÇÃO SUPERIOR, Porto Alegre, 2015. Anais... Porto Alegre, 2015.

VERGARA, Sylvia Constant. Projetos e relatórios de pesquisa em administração. 14. ed. São Paulo: Atlas, 2013. 94 p. 